\title{
Pituitary Abscess: a Report of Two Cases
}

\author{
Maguette Mbaye ${ }^{1^{*}}$, Mbaye Thioub ${ }^{1}$, Yannick Canton Kessely ${ }^{2}$, Ibrahima Tine ${ }^{3}$, Mohamed \\ El Hassimi Cisse ${ }^{2}$, Alioune Badara Thiam ${ }^{1}$, Momar Code Ba ${ }^{4}$, Seydou Boubakar Badiane ${ }^{5}$
}

\author{
${ }^{1}$ MD, Assistant Professor of Neurosurgery, Neurosurgery Clinic, Fann National University Hospital, Dakar, Senegal \\ ${ }^{2}$ MD, Neurosurgeon, Neurosurgery Clinic, Fann National University Hospital, Dakar, Senegal \\ ${ }^{3}$ MD, Assistant Professor of Neurosurgery, Neurosurgery Unit, Hospital Principal, Dakar, Senegal \\ ${ }^{4}$ MD, Professor of Neurosurgery, Neurosurgery Clinic, Fann National University Hospital, Dakar, Senegal \\ ${ }^{5}$ MD, Professor of Neurosurgery, Head of Neurosurgery Clinic, Fann National University Hospital, Dakar, Senegal
}

* Corresponding Author Address: Department of Neurosurgery, Fann University Hospital, Avenue Cheikh Anta Diop, Dakar; Senegal. Tel: +221777067471. Email: maguette.mbaye8@gmail.com

\section{Abstract}

Background and Importance: Abscess of the hypophysis or pituitary adenoma is a very rare entity, and its preoperative diagnosis could be challenging. The clinical presentation is less specific, and despite the recent advancement in imaging, diagnosis before surgery is still difficult.

Case Presentation: We reported two cases of pituitary abscesses in patients aged 38 and 42 years. The first patient was managed for maxillary sinusitis associated with pituitary adenoma whose diagnosis was made following surgery. For the second patient, the diagnosis was proposed before surgery following an MRI which showed a ring enhancement lesion of the hypophysis. Both patients benefitted from surgery where one had sub-labial rhino-septal trans-sphenoidal approach and the other through endoscopic endonasal trans-sphenoidal approach. Both received intravenous broad spectrum antibiotics.

Conclusion: Post-operative evolution was good with control MRI showing complete disappearance of the sellar lesion. Early diagnosis and treatment improved the prognosis.

Keywords: Abscess; Hypophysis; Transphenoidal Approach

Please cite this paper as: Mbaye M, Thioub M, Kessely Y.C, Tine I, Cisse M.E.H, Thiam A.B, Ba M.C, Badiane S.B Pituitary Abscess: a Report of Two Cases. Iran J Neurosurg. 2017;3(1):31-35

\section{Background and Importance}

Pituitary abscess is a rare pathology representing less than $1 \%$ of pathologies of the hypophysis. Heslop in 1848 reported the first case of primary abscess of the hypophysis followed by Simmonds in 1914 [1]. The superinfection of a pituitary adenoma resulting in an abscess is again a much more rare entity with very few cases in the literature, first by Whalley [2]. MRI features of meningeal enhancement, absence of post-hypophyseal signal or of thickened pituitary stalk were suggestive of pituitary abscess [3]. However, confirmation is mostly done after surgery. We reported two cases of pituitary abscess where one was managed for pituitary adenoma whose diagnosis of an associated abscess was surprisingly made intraoperatively and the diagnosis of the second was made preoperatively.

\section{Case Presentation}

\section{Case 1}

A 38-year-old patient who was apparently healthy was presented to the outpatient clinic with one-year headaches resistant to medical treatment associated with visual disorders. On examination, pupils were equal and reactive with a bilaterally reduced visual acuity. There was neither papilledema nor focal motor or sensory deficit. No evidence of gynecomastia was observed when examined. Brain magnetic resonance 
imaging (MRI) showed a voluminous intrasellar lesion measuring $40 \mathrm{~mm}$ in diameter (Figure 1) with a suprasellar extension associated with a mass effect on the optic chiasma by upward displacement. The lesion also extended into the sphenoidal sinus and laterally into the left cavernous sinus. It is a heterogeneous lesion with foci of necrosis and heterogeneous enhancement especially in the suprasellar component. In addition, there was evidence of right maxillary sinusitis.

Complete blood count (CBC) was normal with leucocytes $\left(8.87 \times 10^{3} / \mu \mathrm{L}\right)$. Hormonal profile was normal with thyroid stimulating hormone (TSH) $(1.43 \mu \mathrm{IU} / \mathrm{ml})$ (Normal Range: 0.35-4.94), luteinizing hormone (LH) $(0.76 \mathrm{mIU} / \mathrm{ml})$ (Normal Range: 0.5712.7), follicle stimulating hormone (FSH) (2.62 mIU/ml) (Normal Range: 0.95-11.95), cortisol (122 ng/ml) and prolactin (13.4 ng/ $\mathrm{ml})$.

The indication for surgery (resection of necrosed adenoma) was made after six weeks and the sub-labial rhino-septal transphenoidal approach was employed. After resection of the sphenoidal mucosa, there was an issue of foul smelly yellowish pus and samples were collected for microscopy culture and sensitivity. We then proceeded with piecemeal resection of the tumor.

Results of the histology and immunohistochemistry showed pituitary adenoma with a mild gonadotropic secretion. No growth of any germ was observed in bacteriologic analysis. The patient was boarded on metronidazole, ceftriaxone and gentamicin. Immediate postoperative $\mathrm{CBC}$ showed leukocytosis $12.57 \times 10^{3} / \mu \mathrm{L}$ (Normal Range: $4.0-10.0 \times 10^{3} /$ $\mu \mathrm{L}$ ) dominated by neutrophils with $82.5 \%$. MRI done six weeks postoperatively showed an enlargement of the sellar turcica filled with a non-contrast enhancing solid tissue (Figure 2). Three months post-operative follow up, there was a partial improvement of visual disorder alongside resolution of the headaches and after two years the patient had no symptoms.

Case 2

A 42-year-old housewife, usually healthy, presented with refractory headaches associated with visual blurring of four-month duration. In addition to these symptoms, there were severe asthenia and fever for which she consulted to the clinic. On examination, she had decreased bilateral visual acuity and weight loss. Brain MRI showed a ring enhancement in the pituitary area (Figure 3).

$\mathrm{CBC}$ was normal and hormonal profile showed: ultrasensitive TSH: $1.23 \mathrm{mIU} / \mathrm{L}$ [Normal Range: 0.27-4.20 mIU/L]; LH: 1.23 $\mathrm{mIU} / \mathrm{ml}$ [Normal Range: 2-9]; FSH: 3.37 $\mathrm{mIU} / \mathrm{ml}$ [Normal Range: 2-12], cortisol: 122 $\mathrm{ng} / \mathrm{ml}$ and prolactin: $6.46 \mathrm{IU} / \mathrm{ml}$ [Normal Range:109-560 IU/ml]. There was a relative decrease in adrenocorticotropic hormone $(\mathrm{ACTH})(6.1 \mathrm{pg} / \mathrm{ml})$ and insulin-like growth factor 1 (IGF-1) $(47.7 \mathrm{ng} / \mathrm{ml})$.

Surgical drainage through endoscopic endonasal transphenoidal approach showed evidence of pus after opening the sellar lodge. Microscopic culture and sensitivity did not grow any germ. The patient was then boarded on intravenous ceftriaxone four gram daily and metronidazole 1.5 gram daily for six weeks with temporary post-operative corticotropic supplementation. Clinical postoperative evolution was favorable. MRI done four months and 20 days postoperatively showed absence of focal lesion or intrasellar collection (Figure 4); however, hormonal profile still showed persistent deficit in corticotrope. Follow up at 14 months was uneventful.

\section{Discussion}

Pituitary abscess is a rare pathology representing 0.1 to $1 \%$ of pituitary lesions [1]. Since its first descripotion by Heslop (1848) then by Simmonds (1914) until this day, less than 300 cases have been reported in the literature comprising mostly small series and case reports among which those reported by Vates et al. (24 cases) [4] and Liu (33 cases) [1,5] formed the majority. A modest female predominance was also reported by these authors. The ages of our patients (38 and 42 years) were similar to the mean age reported by Dominigue et al. [7] and Sautner et al. [8] which is 40 years (11-89 years). Generally, there are two types of pituitary abscesses: primary pituitary abscess with $66 \%$ of cases illustrated by our second patient and secondary pituitary abscess on a pathologic hypophysis representing about 34\% which is the first 

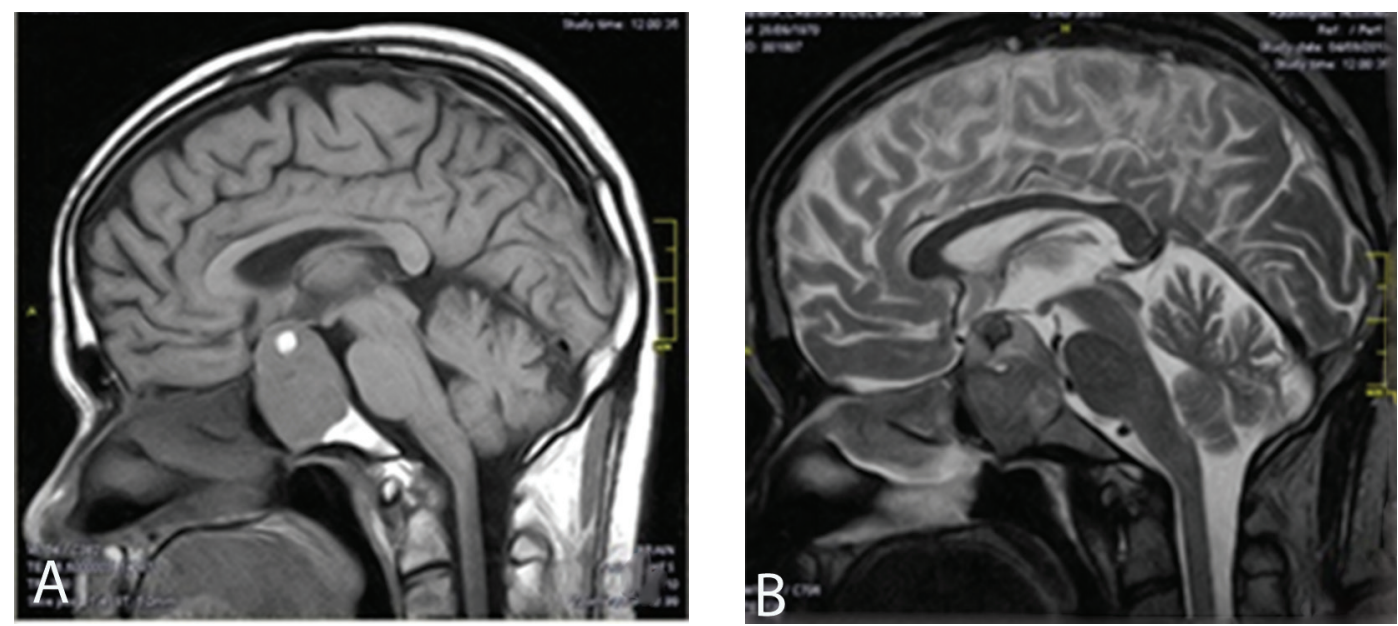

Figure 1. A) Brain MRI Sagittal View T1W1 Sequence B) T2 Sequence Showing a Voluminous Sellar Lesion with Suprasellar Extension that Extends into the Sphenoidal Sinus

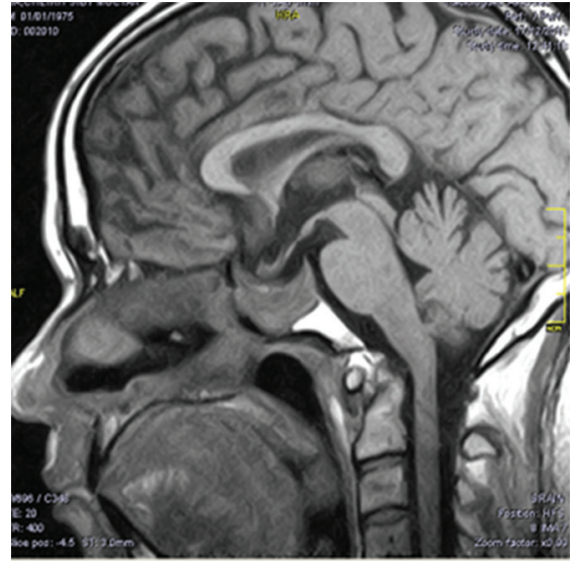

Figure 2. Cerebral MRI on T1-weighted Images, Sagittal Section Performed 47 Days after a Surgery

case in our series. Preexisting pituitary lesions are mostly adenomas followed by Rathke's cleft cysts and craniopharyngioma $[1,5,6]$. Pathophysiologically, contamination is done either by hematogenous or seeding from sinusitis with penetration of the sellar wall barrier (the 38-year-old patient in our series), cavernous thrombophlebitis, dural fistula or meningitis $[6,9,10]$. On the other hand, contamination can also be from direct inoculation following surgery $[1,5]$. Pituitary adenoma infarction, pituitary apoplexy, local immunodeficiency (Cushing's disease) can constitute predisposing factors. In our first case, the abscess developed on a pituitary adenoma with maxillary sinusitis. Bauduceau et al. [11] reported the frequency of maxillary sinusitis in pituitary abscess. Clinically, headache and visual disorders dominated. Usually,

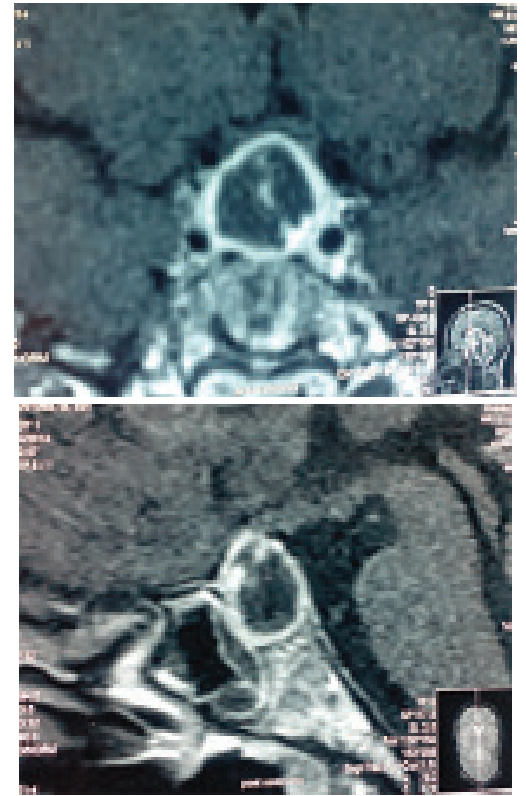

Figure 3. Pituitary Abscess Associated with Sphenoiditis

hormonal disorders can also be associated with mild to moderate deficits. However, it's worth mentioning that diabetes insipidus is more frequent in pituitary abscess than other lesions of the pituitary [1,5]. Hematology is usually non-contributive. Leukocytosis of less than 15000 leucocytes $/ \mathrm{mm}^{3}$ was only seen in $25 \%$.

The first MRI description was made by Jadhay et al [9]. In both CT and MRI, a ring enhancement lesion is mostly suggestive [12], so does thickening of the pituitary stalk. The diagnosis of pituitary abscess regardless of improvement in imaging still remains a challenge due to its 


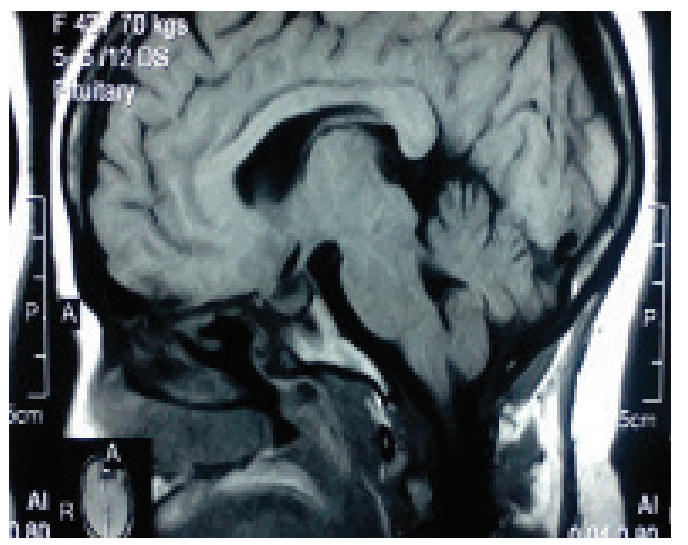

Figure 4. Absence of Focal Lesion or Visible Intra-sellar Collection. The Pituitary Stalk is Centrally Located with no Visible Suprasellar Abnormality

nonspecific nature. The diagnosis is rarely made preoperatively $[13,14]$, and pituitary adenoma is usually the diagnosis suspected and the diagnosis only becomes evident post operatively [11] or at autopsy [15]; however, in our second case preoperative diagnosis was obvious from the imaging. According to Takayasu et al. [12], the differential diagnosis between pituitary adenoma abscess and pituitary macroadenoma is difficult considering the fact that the infectious syndrome is inconsistent. This corresponded exactly to the situation of the first case where a diagnosis of a necrosed adenoma was made preoperatively and there was no clinical infectious syndrome. As opposed to Kuge et al. [14] who followed with MRI six months after diagnosis of a pituitary adenoma, the evolution of changes to the formation of abscess, we are with the opinion that for our first case if an MRI were done shortly before surgery the diagnosis could have been made. In addition, we also noticed leukocytosis in the early postoperative period. According to Baudeceau et al. [11] $50 \%$ of the samples collected for microscopy and culture are sterile, that this was found in our two cases. The most frequent organisms are: Staphylococcus, Streptococcus and Pneumococcus [7], and gram negative organisms are rare. Mycotic organisms are mostly reported in immunocompromised patients [1]. Rare cases of Mycobacterium tuberculosis have also been reported [16]. Regarding treatment, the gold standard is drainage through transphenoidal approach associated with antibiotherapy and then followed by hormonal supplementation where necessary. Endoscopic endonasal transphenoidal approach is a good technique with less complications. The transcranial approaches have the risk of intracerebral dissemination.

Mortality rate is about $10 \%$ but can approach 50\% incases ofmeningoencephalitis [9]. Rare cases of recurrence have also been reported and mostly due to underlying risk factors. According to the literature, after surgical and medical treatment $60 \%$ of cases are completely cured, $30 \%$ are cured with hormonal and visual disorders, $10 \%$ die mostly without surgery or after craniotomy. The frequency of recurrence is $2.5 \%$ [16]. Mortality rises from 30 to $50 \%$ from a non-operated to one associated with a pituitary tumor and meningitis. Mortality can, however, rise to $100 \%$ for non-treated Aspergillus abscess. Early diagnosis and treatment reduces this mortality to less than $8.3 \%[17,18]$.

\section{Conclusion}

Pituitary abscess in general is suppuration of pituitary adenoma which constitutes a rare complication and its diagnosis preoperatively remains a challenge. Consequently, every cystic lesion with ring enhancement of the hypophysis should raise the suspicion of pituitary abscess. The treatment of choice with good results is surgery associated with antibiotherapy. The transphenoidal approach is preferable to limit the risk of intracerebral dissemination.

\section{Funding}

None.

\section{Conflicts of Interest}

The authors declare no conflict of interest.

\section{Author's Contribution}

Conception and Design: Maguette Mbaye, Mbaye Thioub

Data Collection: Yannick Canton Kessely

Drafting the Article: Maguette Mbaye

Critically Revising the Article: All authors

Reviewed Submitted Version of Manuscript:

Alioune Badara Thiam, Momar Code Ba, Seydou Boubakar Badiane

Approved the Final Version of the Manuscript: All authors 


\section{References}

1.Ciappetta P1, Calace A, D'Urso PI, De Candia N. Endoscopic treatment of pituitary abscess: two case reports and literature review. Neurosurg Rev. 2008;31:237-46.

2.Whalley $\mathrm{N}$. Abscess formation in a pituitary adneoma. $\mathrm{J}$ NeurolNeurosurgPsychiat. 1952;15:66-7.

3.Dutta P and al. Pituitary abscess: Report of four cases and review of literature. Pituitary. 2006;9(2):67-273.

4.Vates GE WC, Berger MS. Diagnosis and management of pituitary abscess: A review of twenty-four cases. J Neurosurg. 2001;95:233-41.

5.Altas M, Serefhan A, Silav G, Cerci A, Coskun KK, Elmaci I. Diagnosis and management of pituitary abscess: a case series and review of the literature. Turk Neurosurg. $2013 ; 23$

6.Kotil K BT. Primary Pituitary Abscess Mimicking an Adenoma: A Rare Entity. Turkish Journal of Endocrinology and Metabolism. 2004;3:125-7.

7.Domingue J.N., C.B. Wilson: Wilson: Pituitary abscesses. Report of seven cases and review of the literature. J Neurosurg. 1977;46:601-8.

8.Sautner D., W. Saeger, D.K. Lüdecke, V. Jansen, M.J.A. Puchner. Hypophysitis in surgical and autoptical specimens. Acta Neuropath. 1995;90:637-44.

9.Jadhav RN PD, Dahiwadkar HV. Abscess formation in invasive pituitary adenoma case report. Neurosurgery. 1998;43:616-9.

10. Metellus P. FG, O. Levrier. Abscess-like formation concomitant with pituitary adenoma in Cushing's disease : case report and pathological considerations. Br J Neurosurg. 2002;16:373-5.

11.Bauduceau B, Dolz M, Mayaudon H, Dupuy O, Cosson E, Bordier L, Boyer B et Pernot P. Abcès hypophysaire : une affection rare et méconnue. Mise au point présentée lors des 25es journées françaises d'endocrinologie, nutrition et métabolisme - Paris, 25-26 novembre 2005 [Internet]. Available from: http://asso.orpha.net/AFDI/upload/file/ Abceshypophysaire.doc

12.Takayasu T, Yamasaki F, Tominaga A, Hidaka T, Arita $\mathrm{K}$, Kurisu K. A pituitary abscess showing high signal intensity on diffuision-weighted imaging. Neurosurg Rev. 2006;29:246-8.

13.Kroppenstedt SN, Liebig T, Mueller W, Graf KJ, Lanksch WR, Unterberg AW. Secondary abscess formation in pituitary adenoma after tooth extraction. JNeurosurg. 2001;94:335-8.

14.Kuge A, Sato S, Takemura S, Sakurada K, Kondo R, Kayama T. Abscess formation associated with pituitary adenoma: A case report: Changes in the MRI appearance of pituitary adenoma before and after abscess formation. SurgNeurolInt. 2011;2.

15.Nelson PB, Haverkos H, Martinez AJ, Robinson AG. Abscess formation within pituitary adenoma. Neurosurgery. 1983;12:331-3.

16.Pasqualino $\mathrm{C}$ and al. Endoscopic treatment of pituitary abscess: two case reports and literature review. Neurosurg Rev. 2008 Apr;31(2):237-46.

17.Yen-Hao Su a, Yun Chen b, Sheng-Hong Tseng a. Pituitary abscess. Journal of Clinical Neuroscience. 2006;13:1038-41. 18.Iplikcioglu AC et al. Aspergillus pituitary abscess. Acta Neurochir (Wien). 2004;146:521-4. 